\title{
Interactive comment on "Characteristics of Ground Ozone Concentration over Beijing from 2004 to 2015: Trends, Transport, and Effects of Reductions" by Nianliang Nianliang et al.
}

Nianliang Nianliang et al.

cnl88@163.com

Received and published: 1 January 2017

This manuscript has been further edited for language by Essaystar (http://essaystar.com/Service.html), acompany dedicated to helping international researchers publish their findings in the best English language journals possible. The study was restricted by some necessary conditions such as: we lack of observed data for VOCs during 2008-2015, NOx during 2004-2007, meteorological elements during 2004-2009. So the we cannot analyzed them perfectly. In order to make deep analysis and find valuable scientific information on the $\mathrm{O} 3$ pollution in Beijing,we have done the following aspects of work 1 . We add some further analysis and modify the reviewer's opinion. We applied the NO2 and HCHO VCDs from the OMI products in urban Beijing 
(GY site, $116.33^{\circ} \mathrm{E}, 39.93^{\circ} \mathrm{N}$ ) and combined the corresponding ratios to analyze the chemical sensitivity of PO3. 2. In order to explain the regional reductions effect ,we increased analysis and changed some orders of the text. 3. We further polish and improve the English language in this article and the proof is as follows: If there some more revisions, we will further modify. Thank you! The annex is the english polish proof.

Please also note the supplement to this comment:

http://www.atmos-chem-phys-discuss.net/acp-2016-508/acp-2016-508-AC2-

supplement.pdf

Interactive comment on Atmos. Chem. Phys. Discuss., doi:10.5194/acp-2016-508, 2016. 
English polish proof

Interactive

Review Certificate

comment

To whom it may concern:

This memo certifies that one of our clients has contracted our academic editing service for the following file.

Order Number:

P-201604200528izp

Word Count:

3388 words
Date of the revies.

04/20/16 ( MM/DD/YY)

The English review was conducted using a two-stage process, in which a junior editor first reviewed the file, and then a senior editor conducted a final and more thorough review. All of our ssional.

Documents receiving this certification should be English-ready for publication; however, the author has the ability to accept or reject our suggestions and changes.

We would like to emphasize that our service targets grammar and language edits. We do not rewrite the documents from scratch. If you are dissatisfied with specific revisions, please contact service@essaystar.com

\section{$\sin x$}

Essaystar Group

$+1-208-975-4235$

EssayStar, 93 S Jackson St, Seatlle, WA 98104

Fig. 1. English polish proof 